\title{
STR technique for the detection of contamination by exogenous DNA in paraffin blocks and histological slides
}

\author{
Denise Barcelos ${ }^{*}$ (D), Karina Funabashi, Susana Mazloum, Mariana Fernandes and Leonardo Cardili
}

\begin{abstract}
Gastrointestinal Stromal Tumors (GIST) present different types of mutations that may or may not be sensitive to specific target therapy. The laboratory procedure required to prepare histological sections traditionally demands multiple steps, making the process prone to contamination by exogenous genetic material (DNA). An eventual contamination of the biological sample with exogenous DNA may jeopardize subsequent analysis of mutations. The Short Tandem Repeat (STR) technique is frequently used in forensic science fields and presents a potential application in surgical pathology, especially in situations of suspected sample exchange. In the present study, the objective is to verify the possible contamination by exogenous DNA in gastric GIST samples and to evaluate if the presence of contamination can interfere in the detection of the mutations of interest. We assessed eight gastric GISTs by the Sanger sequencing and STR sequence analyses. Seven samples presented more than one profile, a result interpreted as contamination. Our results indicate that exogenous DNA contamination occurred in most of the samples studied and that this was more frequent in samples obtained from the slides than those obtained from the block. The presence of contamination did not inhibit the detection of the mutations of interest for a specific target therapy. Furthermore, the histologic block revealed to be more advantageously when compared to the slide for molecular pathology diagnosis.
\end{abstract}

Keywords: Contamination by DNA, Repetitive nucleic acid sequences, STR, Paraffin embedment, pharmacogenetics

\section{Introduction}

Detection of mutations of interest for specific therapy target in formalin-fixed and paraffin-embedded samples (FFPE) has become a common practice in pathology laboratories. Increasingly tumor markers are being developed for application in the diagnosis, prognosis and/or prediction of therapeutic response in the most varied types of tumors. In this context, molecular tests have been incorporated into the diagnostic routine, with important impact for the entire diagnostic chain, including for pathologists.

Gastrointestinal Stromal Tumors (GIST) present different types of mutations in KIT (Lasota et al. 2008) and in the PDGFRA (Agaimy et al. 2013) genes, which may or may not be sensitive to specific target therapy (e.g.

\footnotetext{
* Correspondence: barceabra@gmail.com

Departamento de Patologia - Escola Paulista de Medicina, Universidade

Federal de São Paulo, Rua Botucatu, 740 Edifício Lemos Torres, São Paulo, SP CEP 04023-062, Brazil
}

imatinib mesylate) (Boikos et al. 2016). The evaluation of these mutations is performed by molecular methods and definitely contributes to a better therapeutic orientation of the patients (Huss et al. 2015).

The formalin-fixed and paraffin-embedded samples (FFPE) represent an important collection for the diagnosis and research.(Simbolo et al. 2013) In high-demand laboratories, the steps involved in configuring the block can be performed by automated equipment that guarantees efficiency and process control, allowing the processing of several different samples at the same time. On the other hand, plate preparation necessarily involves manual techniques and requires skills of its implementer.

STR (short tandem repeat) analysis is commonly used in forensic science allowing the discrimination of individual profiles based on individual genomic regions of each organism (Jeffreys et al. 1985). The STR regions are non-coding, they always have two alleles and are scattered throughout the genome. The number of 
repetitions within each allele, determines the phenotypic profile of each individual, therefore, when encountered with the presence of an additional profile in the given sample, it is suggestive of sample molecular contamination (Barallon et al. 2010).

In this study, we assessed the exogenous DNA contamination by STR analysis in FFPE samples of gastric GISTs, and we verified whether the presence of contamination interfered in the detection of the mutations of interest.

Due to the large number of steps involved in the preparation of blocks and histological slides, we raised the hypothesis of passive contamination by two different routes: (1) between samples of different patients and; (2) between sample and manipulator cells (Goray and Oorschot 2015; Goray et al. 2010) Fig. 1. Thereby, in this study, we created a proof concept to evaluate the contamination by exogenous DNA through STR sequence analysis of gastric GIST FFPE samples and we tested whether the presence of contamination interfered with the detection of the mutations of interest.

\section{Materials and methods}

We analyzed eight FFPE samples of gastric GIST from different patients. We collected the samples from a diagnostic care center of a hospital affiliated to the Department of Pathology of the Federal University of São Paulo (UNIFESP/EPM), used for the mutational analysis of the KIT gene exon 11 and PDGFRA exon 18 performed by Sanger sequencing for therapeutic planning purposes. Clinical data (sex and age) of the patients from whom the samples were collected were not available.

\section{Sample collection}

In each case, samples were collected by two different methods. Method I consisted of the collection of material directly from the paraffin block (samples B), which was performed with a sterile curette $3 \mathrm{~mm}$ wide. A representative tumor area was determined by a pathologist. These fragments were stored in a sterile tube $(1.5 \mathrm{~mL})$ of microcentrifuge. The authors chose this method in order to eliminate any possible interference related to the steps involved in preparing histology slides. Method II consisted of collecting material directly from the lamina with histological section (L). They removed one to three histological sections of $5 \mu \mathrm{m}$ thickness in a conventional microtome. The obtained micrometric sections were extended in a histological bath and arranged on glass slides (Fig. 1). A representative tumor area was determined by a pathologist. The samples were collected by hand microdissection (direct scraping) on the slide. The collected material was then stored in a sterile tube $(1.5 \mathrm{~mL})$ of microcentrifuge. We emphasize that all the steps of sample collection were performed with sterile instruments (tweezers, scalpel, curette, tubes) and antisepsis procedures. Subsequently, the samples were processed in single batch under the same dewaxing protocol, DNA extraction, mutation analysis and STR analysis.

\section{Criteria for contamination}

To be considered contaminated by exogenous DNA, the sample should present a minimum of two of the 16 analyzed markers, in the following criteria, (1) the presence of more than two alleles per marker or (2) the presence of a discrepancy between the number of replicates for each allele.

\section{DNA extraction and mutation analysis}

The extractions wercommercialed according to the manufacturer's manual (Qiagen QIAamp DNA Micro-commercial kit). The analysis of the mutations of interest for gastric GIST was previously performed by Sanger sequencing method (Merkelbach-Bruse et al. 2010).

\section{Manual macrodissection}

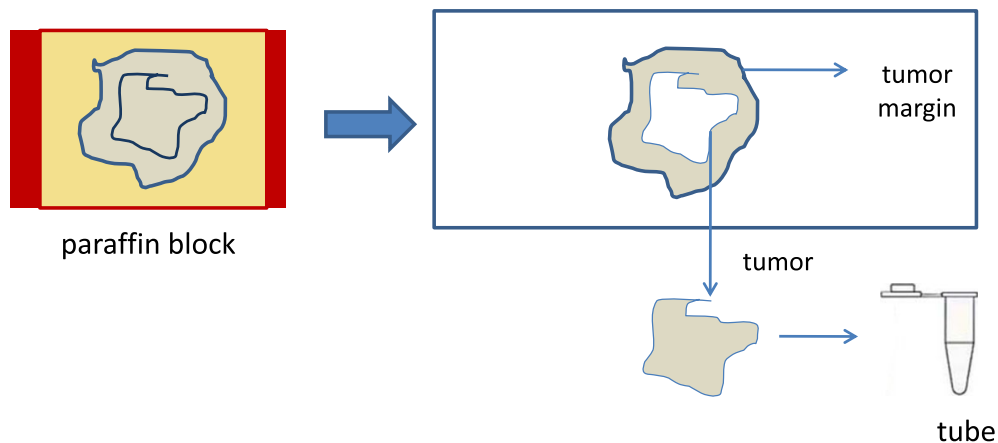

Fig. 1 Study workflow. Study procedure was divided to two analyses: Analysis of mutations for GIST diagnosis by Sanger sequencing and STR analysis for detection of molecular contamination 


\section{Genotyping procedures}

Various markers are used for human identification. In this study, we used the Kit PowerPlex 16 system (White et al. 2015) for STR analysis according to the manufacturer's recommendations (Promega Corporation). A system that has as a sexual marker, the amelogenin and 15 other autosomal markers of different sizes (Table 1). The characterization of the profiles of STR is given by the analysis of all the markers together. This analysis is initiated by the amplification of repetitive regions by PCR and then the fragment sequencing determines the amount of replicates of each allele (Fig. 2) (Morikawa et al. 2011).

The sexual marker is given by amelogenin gene homologous sequences in the $\mathrm{X}$ and $\mathrm{Y}$ chromosomes (AMELX and AMELY). These sequences are amplified simultaneously. Thus, a sample of female origin can be identified by the presence of a single peak derived from the $\mathrm{X}$ chromosome in the electropherogram, while a sample of male origin is characterized by the presence of a secondary peak derived from the $\mathrm{Y}$ chromosome (Morikawa et al. 2011). The presence of two different profiles in the sexual marker (amelogenin) combined with the presence of total compatibility in the other autosomal markers was not considered contamination, since this discrepancy occurred in less than $10 \%$ of the analyzed markers.

The amplification was performed on the GeneAmp ${ }^{\circ}$ PCR System 9700 equipment. Genotyping was performed on the ABI PRISM 3130xl GeneticAnalyzer (AppliedBiosystems). The obtained data were analyzed with the aid of GeneMapper software version 1.2 (AppliedBiosystems). The concentration of DNA used for genotyping was $0,5 \mathrm{ng}$.

\section{Results}

Formalin fixation and paraffin inclusion procedures are part of the routine of all pathology laboratories. The use of automated processing equipment and the high demand for the production of these paraffin blocks and laminates make up a very common scenario that leads for some laboratories to perform several modifications in the standard protocols (Table 2).

\section{Genotyping}

The analysis of amelogenin showed that in all the samples obtained from the slides (samples L) the presence of the marker for the Y chromosome was detected. However, in the samples obtained from the block (samples B), half of the cases (50\%) presented a female sexual pattern, that is, only the presence of a single peak derived from the X chromosome.

The analysis of the autosomal markers showed that the B samples presented a larger amount of amplified markers, independent of contamination, in relation to the samples L (Fig. 3). Comparisons between autosomal markers showed the number of discrepant amplified autosomal markers, independent of contamination, samples L e B (Fig. 4).

\section{GIST mutations}

Sanger sequencing technique was used to detect mutations in all the cases studied. The results obtained in the analysis of mutations in the exon 11 of the KIT gene and PDGFRA gene exon 18 in gastric GIST, presented highquality electropherograms.

\section{Discussion}

In this study, we observed the presence of exogenous DNA contamination in FFPE samples of gastric GISTs. However, this contamination did not inhibit the evaluation of mutations in exon 11 of the KIT gene and the exon 18 of the PDGFRA gene by STR analysis technique.

The purpose of this research was to analyze the possible contamination of samples following the original protocol performed by a molecular pathology laboratory. Furthermore, the initial intention of this project was to attempt an ameliorated understanding of the observed variations between samples processed by the same protocol and that often presented qualitative and quantitative results technically variable.

A previous research evaluated the risk for contamination of tissue samples, it was suggested that standard precautions are sufficient for molecular pathology diagnosis of surgical samples and are not associated with increased risk of cross-contamination, however they limited the investigation solely to the mutation regions of the specific genes (Asor et al. 2017) whereas in this research the investigation of molecular contamination was expanded by the application of STRs.

Accumulating research evidence indicates that STRs make a valuable contribution to the detection of sample exchange or to determine the degree of kinship (Raina et al. 2011; Zhao et al. 2011). However, cautiousness should be taken during the use of STR analysis in tumor samples for forensic purposes, since the loss of heterozygosity or genomic instability caused by tumorigenesis (Pepiński et al. 2009) can lead to errors in the identification of individuals (Filoglu et al. 2014).

Contamination by exogenous DNA may occur due to saliva deposition during sample processing. Saliva is considered one of the main means that can lead to exogenous DNA contamination. Studies demonstrate that the mean number of epithelial cells per $1 \mathrm{~mL}$ of saliva is about $4.3 \times 10^{5}$ (Khare et al. 2014; Quinque et al. 2006) additionally, saliva is one of our body's most accessible bio-fluids, a substantial source of genetic material for either traditional or molecular diagnostic analysis, used 


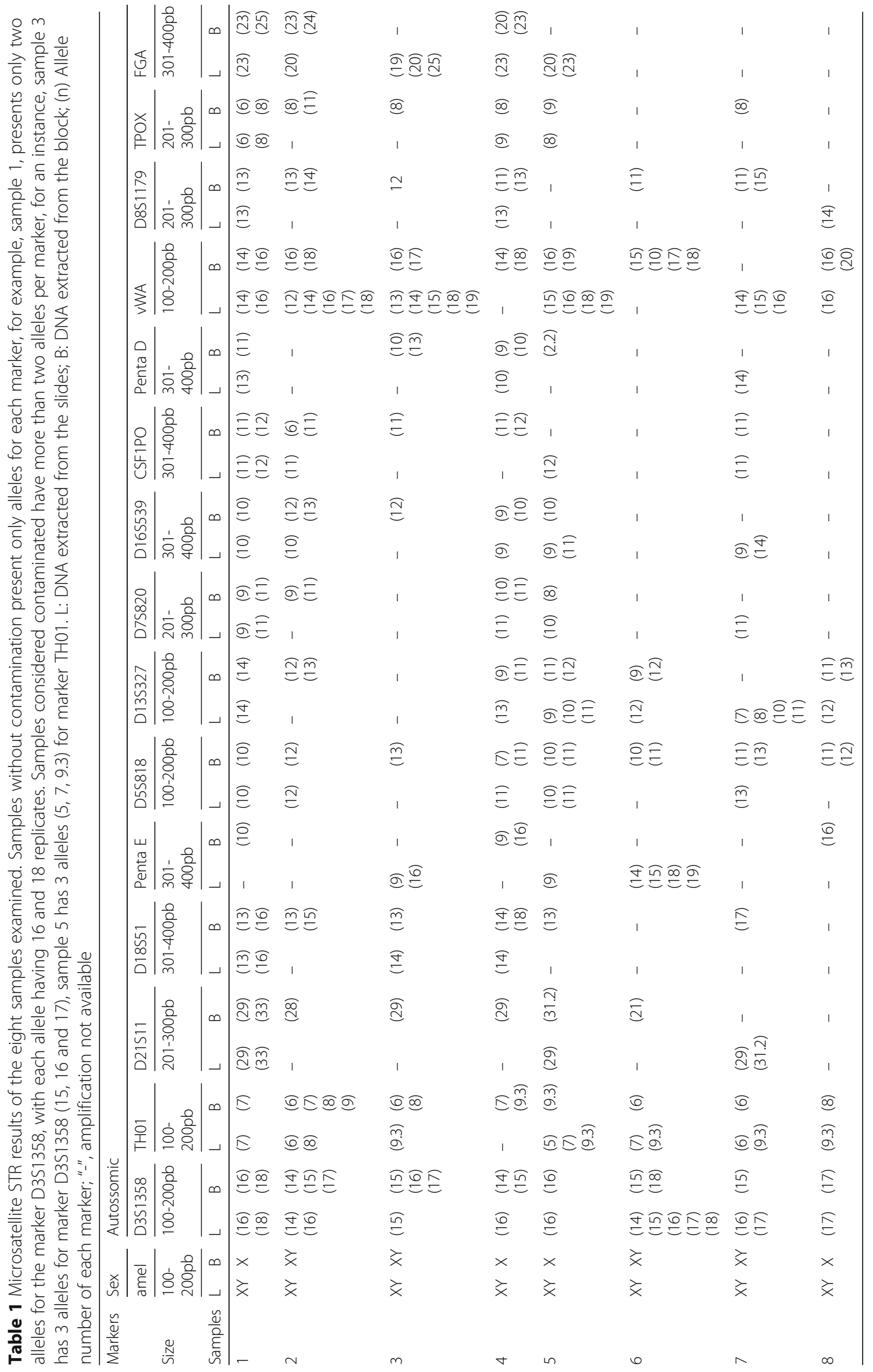




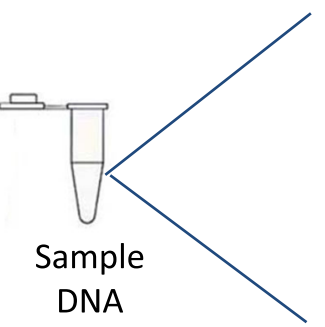

2A

\section{Marker X}

Alelle 1 nnn ATCGATCGATCG nnn

Alelle 2 nnn ATCGATCGATCGATCGATCG nnn

\section{Marker Y}

Alelle $1 \mathrm{nnn}$ ATATATATATATATATATATATATAT $n n n$

Alelle $2 \mathrm{nnn}$ ATATATATATATATATATATATATATAT $\mathrm{nnn}$

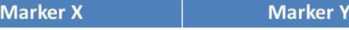

(3) (5)

(13) (14)

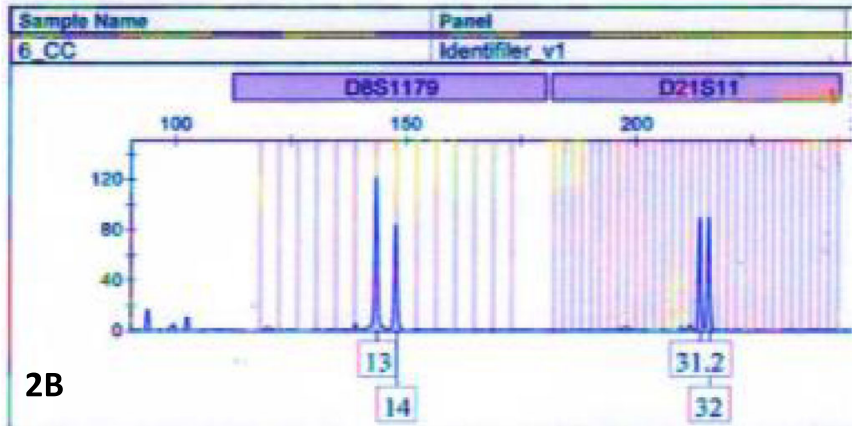

Fig. 2 a Illustrative scheme demonstrating the quantification of the repetitive regions - STR. STR analysis is performed initially by a PCR reaction that amplifies the region where the replications occur. Then the Sequencing is applied, which indicates the number of repetitions that the marker presents. The X-marker presents three and five replicates of each parent allele, while the other Y-marker presents the same number of replicates in the two alleles. $\mathbf{b}$ In the electropherogram, it is possible to see the peaks of two markers indicating the number of repetitions presented by a sample

Table 2 Main modifications occurring in the protocols of fixation, inclusion, diaphanization and microtomy that can lead to endogenous contamination by DNA

\begin{tabular}{|c|c|c|}
\hline Protocols & Protocol modifications & Consequences \\
\hline \multirow[t]{4}{*}{ Fixation } & Inaccuracy in the observation of ideal tissue / formalin volume. & \multirow{2}{*}{$\begin{array}{l}\text { Defective fixation. Free loose cells in the solution } \\
\text { (inter-samples). }\end{array}$} \\
\hline & Decrease in the time required for fixation. & \\
\hline & $\begin{array}{l}\text { The use of the fixative longer than indicated by the manufacturer. Presence of } \\
\text { circulating residues from previous plants. }\end{array}$ & $\begin{array}{l}\text { Presence of circulating residues from previous } \\
\text { samples. }\end{array}$ \\
\hline & $\begin{array}{l}\text { The Personal Protective Equipment (PPE) not utilized by the handlers. DNA } \\
\text { contamination of the manipulator or other component. }\end{array}$ & $\begin{array}{l}\text { DNA contamination from the manipulator or } \\
\text { other component. }\end{array}$ \\
\hline \multirow[t]{2}{*}{ Diaphanization } & $\begin{array}{l}\text { Inaccurate observation of the ideal volumes of alcohol solution within different } \\
\text { concentrations. }\end{array}$ & \multirow[t]{2}{*}{$\begin{array}{l}\text { Mixture of different alcohol solutions, increasing } \\
\text { the risk of fragment exchange. }\end{array}$} \\
\hline & A rapid transfer from one alcohol solution to another. & \\
\hline \multirow[t]{2}{*}{ Inclusion } & $\begin{array}{l}\text { The quality of the paraffin. PPE not utilized by the handlers. Contamination by } \\
\text { saliva. Cells come from previous inclusions. }\end{array}$ & Cells derived from previous inclusions. \\
\hline & Cells from the saliva of the manipulators. & Cells from the saliva from the manipulators. \\
\hline \multirow[t]{2}{*}{ Microtomy } & Reuse of razors for DNA cutting. & \multirow{2}{*}{$\begin{array}{l}\text { Transfer of DNA from the manipulator to the } \\
\text { material (touch). }\end{array}$} \\
\hline & Incorrect block manipulation. Contamination by saliva. & \\
\hline $\begin{array}{l}\text { Histological } \\
\text { slices }\end{array}$ & Incorrect handling. Transfer of DNA from the manipulator to the material (touch) & $\begin{array}{l}\text { Transfer of DNA from the manipulator to the } \\
\text { material (touch) }\end{array}$ \\
\hline
\end{tabular}




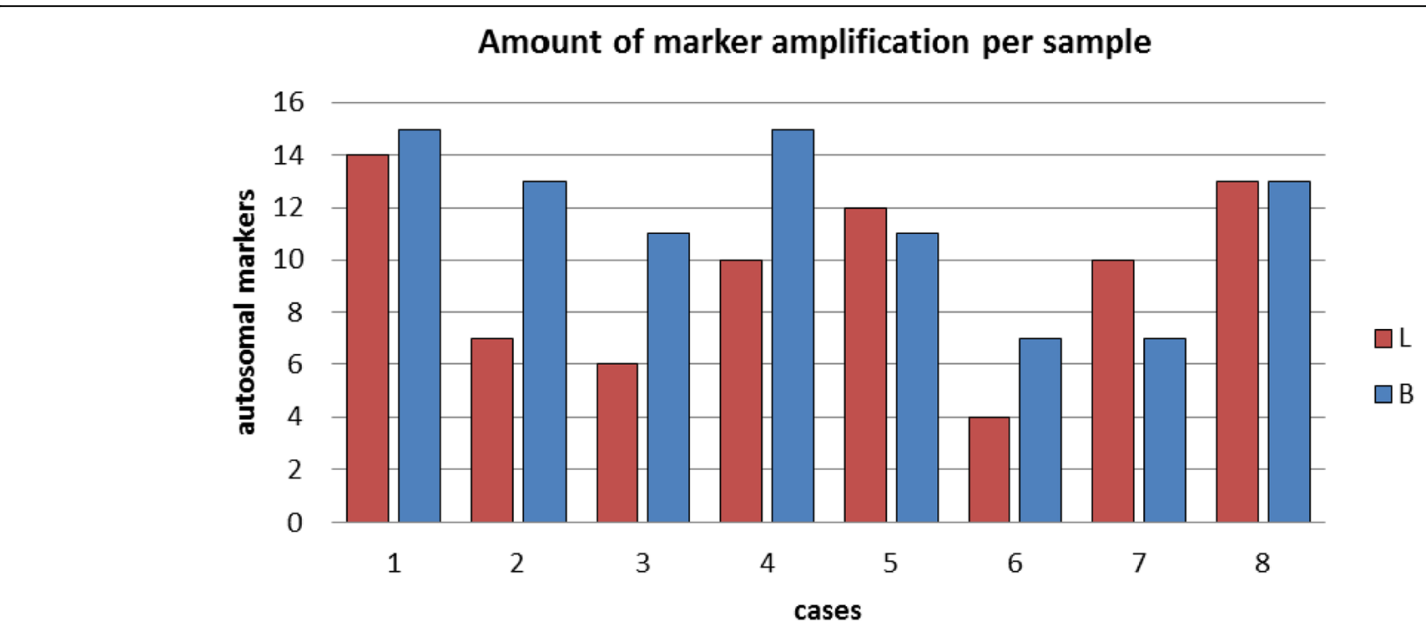

Fig. 3 Amount of amplified markers in accordance with contamination criteria

clinically to detect pathogens and tumor cells (Wang et al. 2015).

DNA from FFPE samples has been found to be partially degraded, sometimes hindering the application of molecular methods (Barcelos et al. 2008). Therefore, the possible presence of a small amount of saliva belonging to the manipulator can decisively interfere with the result of molecular tests (Kidd et al. 2014; Wiegand et al. 2011).

Besides saliva contamination, there is the possibility of contamination by squamous skin cells that can be transmitted by either physical contact between the manipulator and the sample (block or slide) or contamination due to the processing of several samples altogether (Merkelbach-Bruse et al. 2010). Moreover, direct contact can result in the transfer of viable cells and, therefore, of exogenous contaminating DNA, this transferring method is commonly known as "touch DNA" (Malsom et al. 2009; Fonneløp et al. 2015).

In this research, it is also suggested that there may be the possibility of contamination by loose cells during the preparation of the block. Thus, the use of automated extraction equipment and the training of the technical team for the preparation of samples for molecular use can reduce the contamination rates (Lang et al. 2012). Therefore, by being produced specifically for the forensic market, which uses degraded samples and often in very small quantities, the STR kits were used due to the fact that they are highly sensitive and robust allowing the detection of small allele peaks even at very low concentrations.

The amplified marker size is directly related to the detection sensitivity of the marker. The STR detection kit used in this study presents markers in three different

\section{Number of discrepant amplified markers in samples $L$ and $B$}

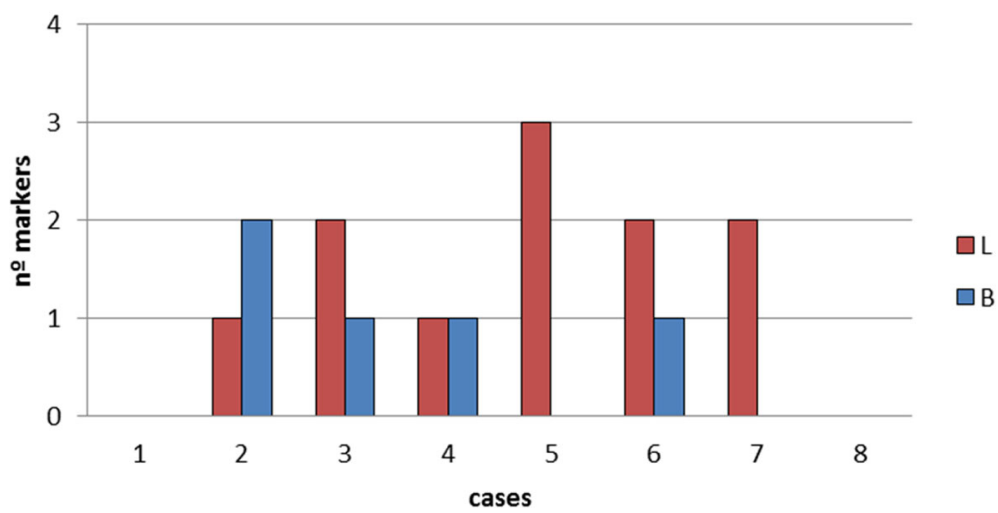

Fig. 4 Comparison between autosomal markers. The number of discrepant amplified autosomal markers, independent of contamination, samples $L$ e B 
sizes, $100-200 \mathrm{bp}, 201-300$ bp e $301-400 \mathrm{bp}$. Amplification of larger fragments indicates molecular integrity whereas amplification of only a few base pair fragments (bp) indicates damage of the DNA molecule. A "one size fits all" approach to the interpretation of these samples is not recommended (Budimlija et al. 2009). Hence, the non-amplification of some markers does not invalidate the results. However, it can lower the similarity rate of the profile sought and therefore the analysis must be conducted carefully to evaluate these profiles (Pelotti et al. 2007).

This sensitivity may explain the discrepant detection of the $\mathrm{Y}$ chromosome marker in samples $\mathrm{L}$ and $\mathrm{B}$ in case 1 , considered uncontaminated. This marker is one of the smaller ones and therefore has an amplification rate higher than the others.

Knowing the genetic profile of the samples manipulator is one of the control parameters in STR analyzes, specifically the gender. This can be a determining factor in a sample exchange case, for example, where other markers cannot be amplified. In our study, the researcher responsible for the sample extractions was a woman and the presence of $Y$ may suggest that sample contamination occurred during the processing of the tissues by a male operator.

The samples used in this study were taken from a reference database in the region and therefore this bank receives material from several other locations, moreover, the samples are often part of the routine as a case review, it is additionally not possible to access basic data such as the patient's name and gender. These samples were specifically included in the study because they presented high-quality results in PCR and in the Sanger sequencing, which is out of the characterized standard when considering the paraffin samples and for that reason, the hypothesis of the contamination emerged.

Samples B not only showed a higher amplification rate of the markers in general, also showing lower amounts of excess peaks, suggesting that the use of $\mathrm{L}$ samples to obtain molecular test material may represent an additional risk of exogenous DNA contamination (Figs. 3 and 4). Such findings are probably due to contaminations that occurred in stages between inclusion and histological cut, given that the water of the histological bath is not replaced for each sample, as it happens with the razors, presenting as a possible route for contamination of the L samples. We also emphasize that although the amount of DNA extracted from the samples B is greater than that obtained from samples $\mathrm{L}$, this does not guarantee the efficiency of the reaction, since such efficiency depends on intact DNA templates without the crosslinking (Funabashi et al. 2012).

The non-amplification of some markers occurred in all the cases studied is related to the fact that the average length of DNA obtained after extraction is $300-400 \mathrm{bp}$. However, this value is lower in FFPE tissues, which reduces the amount of amplified fragments in detectable levels by the equipment (Barcelos et al. 2008; Alqaydi and Roy 2016).

The DNA extracted for the detection of mutations of exon 11 of the KIT gene (174pb) and the exon 18 of the PDGFRA gene (213 bp) was extracted from histological sections. It was possible to amplify all samples, without inhibition of the Sanger sequencing technique by contamination with exogenous DNA, however, samples 2, 5 and 8 did not present mutations in exon 11 of the KIT gene and no sample had mutations in exon 18 of the PDGFRA gene.

Some limiting aspects deserve to be highlighted. The lack of comparison between the DNA profile of the FFPE samples and the DNA profile of fresh samples (blood or tissue) from the same patient represents an important limitation of our study. In addition, studies involving a larger number of samples are necessary since our results are based on a rather reduced casuistry. In the future, separate investigation of each stage of histotechnical processing (fixation, paraffinization, inclusion and shear) may yield relevant results for a better understanding of the means of contamination and provide the basis for a reformulation of standard operating protocols.

\section{Conclusion}

To conclude, we detected the presence of exogenous DNA contamination in FFPE samples of gastric GISTs by STR analysis. Such contamination was seen to occur more frequent in samples obtained from the slides than in those obtained from a block and its presence did not inhibit the detection of mutations of interest for the specific targeting therapy. Our findings further indicate probable sample mishandling during the design and application of standard operating protocols for traditional histotechnical processing that might have resulted in their contamination, additionally taking into consideration that such protocols generally do not take into account the possibility of further analysis by molecular techniques.

\section{Abbreviations \\ FFPE: Formalin-fixed and paraffin-embedded samples; GIST: Gastrointestinal stromal tumors; STR: Short tandem repeat}

\section{Acknowledgements}

The authors would like to thank CAPES Foundation for funding part of the research. The authors also thank Dr. Ricardo Artigiani Neto and Dr. Edna Sadaio Miazato Iwamura presented the biopsies studied and the dedicated and skilled staff Policia Cientifica de São Paulo.

"This manuscript was reviewed by a professional science editor and by a native English-speaking copy editor to improve readability". 


\section{Authors' contributions}

DB was responsible for the design, study design and implementation of the project and drafted the manuscript. KF and MF held the molecular genetic studies and drafted the manuscript. LC participated in the histopathological analysis of biopsies and drafted the manuscript. All authors read and approved the final manuscript.

\section{Funding}

The Capes Foundation funded this research through the research grant.

\section{Availability of data and materials}

Data sharing not applicable to this article as no datasets were generated or analyzed during the current study.

\section{Ethics approval and consent to participate}

The study was approved by the Ethical Committee of Universidade Federal de São Paulo - Plataforma Brasil, reference number 16183.

\section{Consent for publication}

"Not applicable".

\section{Competing interests}

The authors declare that they have no competing interests.

\section{Received: 25 March 2019 Accepted: 12 August 2019}

Published online: 09 September 2019

\section{References}

Agaimy A, Otto C, Braun A, Geddert H, Schaefer IM, Haller F (2013) Value of epithelioid morphology and PDGFRA immunostaining pattern for prediction of PDGFRA mutated genotype in gastrointestinal stromal tumors (GISTs). Int J Clin Exp Pathol 6(9):1839-1846 PMC3759490. Available from: https://www. ncbi.nlm.nih.gov/pubmed/24040448

Alqaydi M, Roy R (2016) Quantitative and qualitative study of STR DNA from ethanol and formalin fixed tissues. Forensic Sci Int 262:18-29 Available from: https://www.ncbi.nlm.nih.gov/pubmed/26963697

Asor E, Stav MY, Simon E, Fahoum I, Sabo E, Ben-lzhak O et al (2017) Risk for molecular contamination of tissue samples evaluated for targeted anticancer therapy. PLoS One 12(3):e0173760

Barallon R, Bauer SR, Butler J, Capes-Davis A, Dirks WG, Elmore E et al (2010) Recommendation of short tandem repeat profiling for authenticating human cell lines, stem cells, and tissues. In Vitro Cell Dev Biol Anim 46(9):727-732

Barcelos D, Franco MF, Leão SC (2008) Effects of tissue handling and processing steps on PCR for detection of mycobacterium tuberculosis in formalin-fixed paraffin-embedded samples. Rev Inst Med Trop Sao Paulo 50(6):321-326 Available from: http://www.ncbi.nlm.nih.gov/pubmed/19082372

Boikos SA, Pappo AS, Killian JK, LaQuaglia MP, Weldon CB, George S et al (2016) Molecular subtypes of KIT/PDGFRA wild-type gastrointestinal stromal tumors: a report from the national institutes of health gastrointestinal stromal tumor clinic. JAMA Oncol 2(7):922-928 Available from: https://www.ncbi.nlm.nih. gov/pubmed/27011036

Budimlija Z, Lu C, Axler-DiPerte G, Seifarth J, Popiolek D, Fogt F et al (2009) Malignant tumors and forensics--dilemmas and proposals. Croat Med J 50(3): 218-227 PMC2702737. Available from: https://www.ncbi.nlm.nih.gov/ pubmed/19480018

Filoglu G, Bulbul O, Rayimoglu G, Yediay FE, Zorlu T, Ongoren S et al (2014) Evaluation of reliability on STR typing at leukemic patients used for forensic purposes. Mol Biol Rep 41(6):3961-3972 Available from: https://www.ncbi. nlm.nih.gov/pubmed/24562624

Fonneløp AE, Egeland T, Gill P (2015) Secondary and subsequent DNA transfer during criminal investigation. Forensic Sci Int Genet 17:155-162 Available from: https://www.ncbi.nlm.nih.gov/pubmed/26005954

Funabashi KS, Barcelos D, Visoná I, e Silva MS, e Sousa ML, de Franco MF et al (2012) DNA extraction and molecular analysis of non-tumoral liver, spleen, and brain from autopsy samples: the effect of formalin fixation and paraffin embedding. Pathol Res Pract 208(10):584-591 Available from: http://www. ncbi.nlm.nih.gov/pubmed/22920941

Goray M, Mitchell RJ, van Oorschot RA (2010) Investigation of secondary DNA transfer of skin cells under controlled test conditions. Leg Med (Tokyo) 12(3): 117-120 Available from: https://www.ncbi.nlm.nih.gov/pubmed/20206575
Goray M, van Oorschot RA (2015) The complexities of DNA transfer during a social setting. Leg Med (Tokyo) 17(2):82-91 Available from: https://www.ncbi. nlm.nih.gov/pubmed/25454534

Huss S, Elges S, Trautmann M, Sperveslage J, Hartmann W, Wardelmann E et al (2015) Expert Rev Anticancer Ther 15(6):623-628 Available from: https://www. ncbi.nlm.nih.gov/pubmed/25831232

Jeffreys AJ, Wilson V, Thein SL (1985) Hypervariable 'minisatellite' regions in human DNA. Nature 314(6006):67-73 Available from: http://www.ncbi.n/m. nih.gov/pubmed/3856104

Khare P, Raj V, Chandra S, Agarwal S (2014) Quantitative and qualitative assessment of DNA extracted from saliva for its use in forensic identification. J Forensic Dent Sci 6(2):81-85 PMC4130022. Available from: http://www.ncbi. nlm.nih.gov/pubmed/25125913

Kidd JM, Sharpton TJ, Bobo D, Norman PJ, Martin AR, Carpenter ML et al (2014) Exome capture from saliva produces high quality genomic and metagenomic data. BMC Genomics 15:262 PMC4051168. Available from: http://www.ncbi.nlm.nih.gov/pubmed/24708091

Lang PO, Govind S, Dramé M, Aspinall R (2012) Comparison of manual and automated DNA purification for measuring TREC in dried blood spot (DBS) samples with qPCR. J Immunol Methods 384(1-2):118-127 Available from: https://www.ncbi.nlm.nih.gov/pubmed/22867745

Lasota J, Corless CL, Heinrich MC, Debiec-Rychter M, Sciot R, Wardelmann E et al (2008) Clinicopathologic profile of gastrointestinal stromal tumors (GISTs) with primary KIT exon 13 or exon 17 mutations: a multicenter study on 54 cases. Mod Pathol 21(4):476-484 Available from: https://www.ncbi.nlm.nih. gov/pubmed/18246046

Malsom S, Flanagan N, McAlister C, Dixon L (2009) The prevalence of mixed DNA profiles in fingernail samples taken from couples who co-habit using autosomal and Y-STRs. Forensic Sci Int Genet 3(2):57-62 Available from: http://www.ncbi.nlm.nih.gov/pubmed/19215872

Merkelbach-Bruse S, Dietmaier W, Füzesi L, Gaumann A, Haller F, Kitz J et al (2010) Pitfalls in mutational testing and reporting of common KIT and PDGFRA mutations in gastrointestinal stromal tumors. BMC Med Genet 11: 106 PMC2910708. Available from: https://www.ncbi.nlm.nih.gov/pubmed/205 98160

Morikawa T, Yamamoto Y, Miyaishi S (2011) A new method for sex determination based on detection of SRY, STS and amelogenin gene regions with simultaneous amplification of their homologous sequences by a multiplex PCR. Acta Med Okayama 65(2):113-122 Available from: https://www.ncbi.nlm. nih.gov/pubmed/21519369

Pelotti S, Ceccardi S, Alù M, Lugaresi F, Trane R, Falconi M et al (2007) Cancerous tissues in forensic genetic analysis. Genet Test 11(4):397-400 Available from: https://www.ncbi.nlm.nih.gov/pubmed/18294056

Pepiński W, Sołtyszewski I, Skawrońska M, Rogowski M, Zalewska R, Kozłowski L et al (2009) Loss of heterozygosity ( $\mathrm{LOH}$ )--implications for human genetic identification. Folia Histochem Cytobiol 47(1):105-110 Available from: https:// www.ncbi.nlm.nih.gov/pubmed/19419947

Quinque D, Kittler R, Kayser M, Stoneking M, Nasidze I (2006) Evaluation of saliva as a source of human DNA for population and association studies. Anal Biochem 353(2):272-277 Available from: http://www.ncbi.nlm.nih.gov/ pubmed/16620753

Raina A, Yadav B, Ali S, Dogra TD (2011) Identification of tumor specimens by DNA analysis in a case of histocytological paraffin tissue block swapping. Croat Med J 52(3):410-414 PMC3118722. Available from: https://www.ncbi. nlm.nih.gov/pubmed/21674839

Simbolo M, Gottardi M, Corbo V, Fassan M, Mafficini A, Malpeli G et al (2013) DNA qualification workflow for next generation sequencing of histopathological samples. PLoS One 8(6):e62692 PMC3675123. Available from: http://www.ncbi.nlm.nih.gov/pubmed/23762227

Wang Y, Springer S, Mulvey CL, Silliman N, Schaefer J, Sausen M et al (2015) Detection of somatic mutations and HPV in the saliva and plasma of patients with head and neck squamous cell carcinomas. Sci Transl Med 7(293): 293ra104 PMC4587492. Available from: https://www.ncbi.nlm.nih.gov/ pubmed/26109104

White J, Hughes-Stamm S, Gangitano D (2015) Development and validation of a rapid PCR method for the PowerPlex ${ }^{\otimes} 16$ HS system for forensic DNA identification. Int J Legal Med 129(4):715-723 Available from: https://www. ncbi.nlm.nih.gov/pubmed/25381196

Wiegand P, Heimbold C, Klein R, Immel U, Stiller D, Klintschar M (2011) Transfer of biological stains from different surfaces. Int J Legal Med 125(5):727-731 Available from: http://www.ncbi.nlm.nih.gov/pubmed/20195624 
Zhao SM, Zhang SH, Li CT (2011) A primary study of criterion for source identification of gastrointestinal tumor sample with identifiler multiplex system. Fa Yi Xue Za Zhi 27(2):102-106 Available from: https://www.ncbi.nIm. nih.gov/pubmed/21604447

\section{Publisher's Note}

Springer Nature remains neutral with regard to jurisdictional claims in published maps and institutional affiliations.

Ready to submit your research? Choose BMC and benefit from:

- fast, convenient online submission

- thorough peer review by experienced researchers in your field

- rapid publication on acceptance

- support for research data, including large and complex data types

- gold Open Access which fosters wider collaboration and increased citations

- maximum visibility for your research: over $100 \mathrm{M}$ website views per year

At $B M C$, research is always in progress.

Learn more biomedcentral.com/submissions 